\title{
Bone metabolism is a key factor for clinical outcome of tibial plateau fractures
}

\author{
Matthias Krause ${ }^{1}$ (1) Lena Alm $^{2} \cdot$ Markus Berninger $^{1} \cdot$ Christoph Domnick $^{3} \cdot$ Kai Fehske $^{4} \cdot$ Karl-Heinz Frosch $^{1}$. \\ Elmar Herbst ${ }^{3}$ - Alexander Korthaus ${ }^{1} \cdot$ Michael Raschke ${ }^{3} \cdot$ Reinhard Hoffmann ${ }^{5}$. The "Fracture committee" of the \\ German Knee Society
}

Received: 24 May 2020 / Accepted: 28 October 2020 / Published online: 5 November 2020

(c) The Author(s) 2020

\begin{abstract}
Purpose Given that tibial plateau fractures (TPF) are rare, they may pose a challenge to the treating surgeon due to their variety of complex fracture patterns. Numerous studies have identified potential fracture-specific, surgery-related, and patientrelated risk factors for impaired patient outcomes. However, reports on the influence of bone metabolism on functional outcomes are missing.

Methods In a retrospective multicenter cohort study, 122 TPF of 121 patients were analyzed with respect to radiological and clinical outcomes (Rasmussen) with a mean follow-up of $35.7 \pm 24.9$ months. The risk factor assessment included bone metabolism-affecting comorbidities and medication.

Results The findings showed that $95.9 \%$ of the patients reported a good-to-excellent clinical outcome, and $97.4 \%$ reported a good-to-excellent radiological outcome. Logistic regression revealed that potentially impaired bone metabolism (IBM) was an independent risk factor for the clinical $(p=0.016)$ but not the radiological outcome (Table 4). Patients with 41-type $\mathrm{B}$ fractures and a potential IBM had a seven times higher risk to present a fair-to-poor clinical outcome [OR 7.45, $95 \mathrm{CI}$ $(4.30,12.92)]$. The most common objective impairment was a limited range of motion in $16.4 \%$ of the patients, especially in 41-type $\mathrm{C}$ fractures $(p=0.06)$. The individual failure analysis additionally identified surgery-related options for improvement. Conclusion This study demonstrated that potential IBM was an independent risk factor for a poor-to-fair clinical outcome.
\end{abstract}

Keywords Tibial plateau fracture $\cdot$ Bone metabolism $\cdot$ Ten-segment classification $\cdot$ Follow-up $\cdot$ Failure analysis

Matthias Krause

m.krause@uke.de

1 Department of Trauma and Orthopaedic Surgery, University Medical Center Hamburg-Eppendorf, Martini Str. 52, 20246 Hamburg, Germany

2 BG Trauma Hospital Hamburg, Hamburg, Germany

3 Department of Trauma, Hand and Reconstructive Surgery, University Hospital Münster, Münster, Germany

4 Department of Orthopaedic Trauma, Hand, Plastic and Reconstructive Surgery, University Hospital Würzburg, Würzburg, Germany

5 Department of Trauma and Orthopaedic Surgery, Berufsgenossenschaftliche Unfallklinik Frankfurt Am Main, Frankfurt am Main, Germany

\section{Introduction}

Given that tibial plateau fractures (TPF) are rare, they may pose a challenge to the treating surgeon due to their variety of complex fracture patterns [1]. There are numerous approach concepts to improve surgical outcome of TPF, including the updated three-column, the revised threecolumn, which is a mechanism-driven approach, and the ten-segment concept [1-5]. Nonetheless, persistent pain, impaired range of motion (ROM), and/or instability are repeatedly described. While short- and mid-term outcomes have been associated with a low return-to-sports rate and a low patient-related outcome compared to healthy individuals (Knee Injury and Osteoarthritis Outcome Score), a good-toexcellent knee function in the long term has been reported (Rasmussen and Hospital for Special Surgery Knee Scoring System) [6-10]. Several studies have identified potential fracture-specific and surgery-related risk factors for impaired 
patient outcomes [6-11]. As a result, there is general consensus that anatomical reconstruction within a $2-3-\mathrm{mm}$ articular step-off, a straight leg axis, and stable bony and ligamentous fixation should be considered [9, 11-14].

While some studies have also analyzed the influence of patient-specific risk factors, medication, or comorbidities, their association with bone metabolism and its impact on patient outcomes has not been in the focus [6, 7, 10, 15-17]. Instead, impaired bone metabolism (IBM) and its association with patient-specific risk factors such as vitamin D deficiency, thyroid dysfunction, chronic kidney disease (CKD) or liver failure, systemic immunodeficiency after organ transplantation or with HIV, or osteoporosis itself have most commonly been studied in relation to fracture risk of vertebral and hip fractures. The influence of vitamin D deficiency on bone health is undisputed and seems to have a negative impact on fracture healing [18]. Other endocrine diseases like hyperthyroidism, renal, or liver failure are also common in descending order of prevalence and relate to increased fracture risk (hyperthyroidism: from 17 to $97 \%$ ) depending on location of the fracture site $[19,20]$.

While the exact prevalence of IBM is unclear, many of its associated risk factors such as a vitamin D deficiency (up to $40.4 \%$ ), which may be called pandemic in western Europe, CKD (up to 10.6\%), and hyperthyroidism (up to $1.3 \%$ ) are common [21-23]. Osteoporosis, the most obvious reason for IBM, is prevalent in 35\% of all postmenopausal white women, further increasing with age [24]. Therefore, the impact of a potential IBM on fracture risk, subsequent fracture healing, and postoperative patient outcome in TPF is conceivable and still underrated.

The aim of this study was to analyze patient outcome after surgical treatment of TPF and to evaluate the potential influence of patient comorbidities affecting bone metabolism on surgical outcome. We hypothesized that patients with accompanying bone metabolism-affecting comorbidities or medication showed a worse outcome than patients without known potentially impaired bone metabolism (IBM). We also aimed to present an individual failure analysis of patients with a poor-to-fair functional outcome (Rasmussen) after open reduction and internal fixation (ORIF) of TPF.

\section{Patients and methods}

\section{Study group}

This retrospective multicenter cohort study analyzed all consecutive patients who were surgically treated at a level-one trauma center from June 2010 to December 2015 from a study group that was previously reported on [1]. We included all patients with a minimum follow-up of 12 months and excluded patients without a preoperative computed tomography (CT) scan, extra-articular fracture manifestation (Orthopedic Trauma Association/AO Foundation (OTA/AO) type A), and periprosthetic fractures. In addition to the assessment of patient-related outcome measures (Rasmussen), electronic data files were carefully searched for comorbidities that could potentially influence bone metabolism according to the present $\mathrm{S} 3$ guideline on the treatment of osteoporosis in Germany [25]. Hence, a potentially impaired bone metabolism (IBM) was defined as the presence of hyperthyroidism, primary hyperparathyroidism, Cushing syndrome, chronic kidney disease grade $3 \mathrm{a}$ and above, human immunodeficiency virus (HIV), diabetes mellitus, vitamin D deficiency (serum level $<50 \mathrm{nmol} / \mathrm{L}$ ), rheumatoid arthritis, and/or osteoporosis according to the WHO standard definition of a femoral or hip DXA T-score $-2.5 \mathrm{SD}$ or lower. Specific risk factors, such as smoking, alcohol abuse, low body mass index (BMI), or medication, including chemotherapeutic agents, cortisol, and specific anti-retroviral medication were also assessed but not automatically categorized to an IBM. The study protocol was approved by the local ethics committee (WF-02/16).

\section{Surgical treatment}

TPF were categorized according to the OTA/AO and 10-segment classification [1, 26-28]. All cases were surgically managed, including the choice of the surgical approach and potential placement of the osteosynthesis, based on the concept of the ten-segment classification to evaluate the intraarticular fracture run in addition to the 3-column concept for extra-articular fracture manifestation [27-31]. Management included the application of an external fixator in cases of serious soft-tissue damage and screw fixation in minor depression fractures (OTA/AO Type B2). Unilateral split-depression fractures were usually treated with screw and plate fixation (OTA/AO type B3), while bilateral fractures were treated with dual plate and screw fixation (OTA/ AO type $\mathrm{C}$ ). The number and combination of surgical approaches are given in Table 1. Certified trauma surgeons performed all procedures. Postoperatively, rehabilitation protocols differed, depending on the fracture pattern, softtissue injury, and surgical treatment. In general, all patients started with physiotherapy within the first week after softtissue consolidation. Except for some cases with ligament injuries or posterior fragment involvement, patients were mobilized without a knee brace and were recommended to gradually increase knee flexion. All patients were kept partial weight bearing for at least 6 weeks postoperatively.

\section{Outcome measures}

Patient-reported outcome measures and radiological followups were obtained according to the clinical and radiological 
Table 1 Patient characteristics with regards to fracture type according to OTA/AO classification $(n=122)$

\begin{tabular}{|c|c|c|c|}
\hline Characteristics & OTA/AO type B $(n=85)$ & OTA/AO type C $(n=37)$ & Type B vs. type C $p$ value \\
\hline Sex ratio $\left(n ;+/{ }^{\Uparrow}\right)$ & $48 / 37$ & $19 / 18$ & Ns \\
\hline Age $( \pm \mathrm{SD}$, years; + /ふ̋) & $52.5 \pm 19.1 / 43.8 \pm 12.7$ & $60.1 \pm 6.4 / 48.5 \pm 8.4$ & $0.014 /<0.001$ \\
\hline \multicolumn{4}{|l|}{ Mechanism of trauma } \\
\hline High energy $(n ;$ ○/ふ) & $25 / 34$ & $12 / 16$ & $<0.001 / 0.042$ \\
\hline Low energy $(n ; \uparrow / ふ)$ & $23 / 3$ & $7 / 2$ & \\
\hline \multicolumn{4}{|l|}{ Risk factors $(n ;+/ ふ)$} \\
\hline Smoking & $1 / 12$ & $1 / 7$ & $<0.001 / 0.013$ \\
\hline Diabetes & $1 / 1$ & $1 / 1$ & $\mathrm{~ns} / \mathrm{ns}$ \\
\hline Impaired bone metabolism & $10 / 4$ & $5 / 5$ & $\mathrm{~ns} / \mathrm{ns}$ \\
\hline BMI (mean: kg/m²) & $22.0 \pm 2.7 / 27.1 \pm 5.2$ & $27.0 \pm 6.7 / 27.1 \pm 2.8$ & $<0.001 / \mathrm{ns}$ \\
\hline \multicolumn{4}{|l|}{ Surgical approaches $(n)$} \\
\hline CRIF with jail technique & 13 & 0 & \\
\hline Anterolateral & 57 & 8 & \\
\hline Posterolateral & 2 & 3 & \\
\hline Anteromedial & 6 & 1 & \\
\hline Posteromedial & 1 & 2 & \\
\hline Median & 1 & 1 & \\
\hline Combination $\mathrm{AL}+\mathrm{PM}$ & 3 & 9 & \\
\hline Combination $\mathrm{AM}+\mathrm{PM}$ & 0 & 2 & \\
\hline Combination $\mathrm{AM}+\mathrm{AL}$ & 0 & 5 & \\
\hline Combination PL + PM & 2 & 2 & \\
\hline Combination $\mathrm{AL}+\mathrm{AM}+\mathrm{PM}$ & 0 & 3 & \\
\hline Combination $\mathrm{AL}+\mathrm{AM}+\mathrm{PL}$ & 0 & 1 & \\
\hline
\end{tabular}

$n s$ not significant, $S D$ standard deviation, $B M I$ body mass index, $C R I F$ closed reduction internal fixation, $A L$ anterolateral, $P L$ posterolateral, $A M$ anteromedial, $P M$ posteromedial

Rasmussen score [32]. Clinical and radiological outcome were categorized according to the total sum of Rasmussen score: clinical score-excellent (30-27 points), good (26-20), fair (19-10), poor (9-6); radiological score excellent (18 points), good (17-12), fair (11-6), poor (5-0) [33]. All patients were given a questionnaire regarding their subjective outcome and were evaluated with respect to their objective clinical findings. Radiological evaluation included preoperative and postoperative conventional $\mathrm{X}$-rays in antero-posterior and lateral views at the time of their followup. Coronal alignment of the proximal tibia was assessed by analyzing the mechanic medial proximal tibial angle (norm $87 \pm 3^{\circ}$ ) [12, 34]. Postoperative radiological follow-up was available for 76 patients. Evaluation of all radiological films was performed by an experienced consultant who specialized in orthopedic trauma.

\section{Statistical analysis}

Statistical analysis was carried out using IBM $^{\circledR}$ SPSS $^{\circledR}$ Statistics 26 (SPSS Inc, Chicago, IL, USA). Data were presented as mean values \pm standard deviation for continuous variables. A Student's $t$ test was used to determine the significance of differences between fracture groups, within group differences, and clinical and radiological categories and between the sexes. Differences among categorical data were tested with a Chi-square test. Binary logistic regression analysis was performed to test the influence of fracture type and the presence of a potential IBM on clinical and radiological outcomes (Rasmussen). All tests were two-sided, and a $p$ value of $<0.05$ was considered statistically significant.

\section{Results}

\section{Study group}

We included a total of 121 patients (males $n=55$, females $n=66$ ) with $122 \mathrm{TPF}$; one patient presented with bilateral TPF. The mean age at operation was $50.6 \pm 15.4$ years. The clinical follow-up period ranged from 12 to 111 months, with a mean of $35.7 \pm 24.9$ months. The radiological followup was significantly shorter $(22.4 \pm 12.5$ months, $p<0.001)$. The baseline characteristics are presented in Table 1. Using the OTA/AO classification, we analyzed 85 cases with a 41-type B fracture [B1: $n=3$ (2.3\%), B2: $n=45$ (35.2\%), 
Table 2 Mean clinical results to fracture type according to OTA/AO classification $(n=122)$

\begin{tabular}{llll}
\hline & $\begin{array}{l}\text { OTA/AO type } \\
\mathrm{B}(n=85)\end{array}$ & $\begin{array}{l}\text { OTA/AO type } \\
\mathrm{C}(n=37)\end{array}$ & $\begin{array}{l}\text { Type B/ } \\
\text { type C } p \\
\text { value }\end{array}$ \\
\hline $\begin{array}{l}\text { Rasmussen (total) } \\
\text { Subjective }\end{array}$ & $27.9 \pm 2.8$ & $26.0 \pm 4.1$ & 0.015 \\
$\quad$ Pain & $5.1 \pm 1.4$ & $4.8 \pm 1.6$ & $\mathrm{~ns}$ \\
$\quad$ Walking capacity & $5.5 \pm 1.1$ & $4.8 \pm 1.6$ & 0.018 \\
Objective & & & \\
$\quad$ Extension & $5.8 \pm 0.7$ & $5.5 \pm 1.0$ & $\mathrm{~ns}$ \\
$\quad$ Total range of motion & $5.7 \pm 0.8$ & $5.2 \pm 0.8$ & 0.006 \\
Stability & $5.9 \pm 0.4$ & $5.8 \pm 0.5$ & $\mathrm{~ns}$ \\
\hline
\end{tabular}

$n s$ not significant

Table 3 Mean radiological results according to OTA/AO classification $(n=122)$

\begin{tabular}{lccl}
\hline & $\begin{array}{l}\text { OTA/AO type } \\
\mathrm{B}(n=54)\end{array}$ & $\begin{array}{l}\text { OTA/AO type } \\
\mathrm{C}(n=22)\end{array}$ & $\begin{array}{l}\text { Type B/ } \\
\text { type C } p \\
\text { value }\end{array}$ \\
\hline Rasmussen (total) & $17.6 \pm 1.3$ & $15.8 \pm 3.3$ & 0.001 \\
Depth & $5.9 \pm 0.5$ & $5.0 \pm 1.7$ & 0.001 \\
Wide & $5.9 \pm 0.6$ & $5.8 \pm 0.6$ & $\mathrm{~ns}$ \\
Angulation & $5.8 .+0.7$ & $5.0 . \pm 1.3$ & 0.001 \\
\hline
\end{tabular}

$n s$ not significant

B3: $n=37(28.9 \%)]$ and 37 cases with a 41-type $\mathrm{C}$ fracture
[C1: $n=9$ (7.3\%), C2: $n=2$ (1.6\%), C3: $n=26$ (21.3\%)]. Two patients presented with an open fracture, and one compartment syndrome had to be treated. Twelve patients $(9.8 \%)$ required temporary immobilization with an external fixator. The mean delay to final surgery due to soft-tissue consolidation was $4.1 \pm 3.5$ days (range: $0-25$ days).

\section{Clinical and radiological outcome}

Overall, 95.9\% ( $n=117)$ of the sampled patients reported a good-to-excellent clinical outcome. The radiological outcome was excellent in $76.3 \%$ and good in another $21.1 \%$ of the cases. Patients with 41-type B fractures showed a significantly better clinical $(27.9 \pm 2.8$ vs. $26.0 \pm 4.1 ; p=0.015)$ and radiological $(17.6 \pm 1.3$ vs. $15.8 \pm 3.3 ; p=0.021)$ Rasmussen Score than those with 41-type $\mathrm{C}$ fractures (Tables 2, 3 , and 4). Inferior clinical knee function was not associated with the follow-up period. The most common objective impairment was limited ROM in $16.4 \%(n=21)$ of the patients, especially in 41-type $\mathrm{C}$ fractures $(p=0.06)$.

\section{Influence of potential IBM}

A potential IBM was detected in $19.7 \%$ of the patients $(n=24)$. These included osteoporosis $(n=7)$, hyperthyroidism $(n=6)$, high-grade liver cirrhosis $(n=3)$, severe vitamin D deficiency $(n=2,[35])$, high-grade ( $>$ grade 3 ) chronic renal failure $(n=2)$, chronic type-c gastritis $(n=2$, one patient with unspecified collagenosis), and $\operatorname{HIV}(n=2)$.
Table 4 Clinical $(n=122)$ and radiological outcome $(n=76)$ according to categories: poor/ fair vs. good/excellent

\begin{tabular}{lllll}
\hline & $\begin{array}{l}\text { Radiological } \\
\text { poor/fair }\end{array}$ & $\begin{array}{l}\text { Radiological } \\
\text { good/excellent }\end{array}$ & Clinical poor/fair & $\begin{array}{l}\text { Clinical } \\
\text { good/excel- } \\
\text { lent }\end{array}$ \\
\hline $\begin{array}{l}\text { Radiological poor/fair } \\
\text { Radiological good/excellent }\end{array}$ & - & - & 1 & 1 \\
Clinical score & & - & 2 & $72^{\#}$ \\
$\quad$ Subjective & & & & \\
$\quad$ Pain & $2.0 \pm 2.8$ & $5.0 \pm 1.3^{*}$ & $0.3 \pm 0.8$ & $5.2 \pm 1.1^{*}$ \\
$\quad$ Walking capacity & $1.0 \pm 1.4$ & $5.5 \pm 0.9^{*}$ & $1.7 \pm 1.4$ & $5.5 \pm 1.0^{*}$ \\
Objective & & & & $5.2 \pm 0.8$ \\
$\quad$ Extension & $5.0 \pm 1.4$ & $5.5 \pm 0.9$ & $5.2 \pm 1.0$ & $5.5 \pm 0.8^{*}$ \\
$\quad$ Total range of motion & $4.0 \pm 0.0$ & $5.6 \pm 0.9^{*}$ & $4.7 \pm 1.0$ & $5.9 \pm 0.4$ \\
$\quad$ Stability & $6.0 \pm 0.0$ & $6.0 \pm 0.2$ & $5.8 \pm 0.4$ & $5.8 \pm 0.9^{*}$ \\
Radiological score & & & & $5.9 \pm 0.5$ \\
Depth & $1.0 \pm 1.4$ & $5.8 \pm 0.7^{*}$ & $2.7 \pm 1.2$ & $5.6 \pm 0.9^{*}$ \\
$\quad$ Wide & $5.0 \pm 1.4$ & $5.9 \pm 0.5^{*}$ & $5.3 \pm 1.2$ & $20 / 96^{\#}$ \\
Angulation & $3.0 \pm 1.4$ & $5.6 \pm 0.9^{*}$ & $4.0 \pm 0.0$ & $82 / 34$ \\
Potential IBM (yes/no) & $1 / 1$ & $13 / 61$ & $4 / 2$ & \\
Fracture category (Type B/C) & $0 / 2$ & $54 / 20^{\#}$ & $3 / 3$ & \\
\hline$p<0.05$ & & & & \\
* Student's $t$ test & & & & \\
\# Chi-square test: $p<0.05$ & & & & \\
\end{tabular}


Logistic regression revealed that potential IBM was an independent risk factor for the clinical $(p=0.016)$ but not for the radiological outcome (Table 5). Patients with 41-type B fractures and potential IBM had a seven times more likely risk of having a fair-to-poor clinical outcome [OR 7.45, 95 CI $(4.30,12.92)]$.

Mean BMI was $25.2 \pm 4.9 \mathrm{~kg} / \mathrm{m}^{2}$. Only three patients presented with an underweight BMI $\left(<18.5 \mathrm{~kg} / \mathrm{m}^{2}\right)$. Smoking was observed in $17.2 \%$ of the patients $(n=21)$. Smoking, BMI, and diabetes showed no significant association with either the radiological or the clinical outcome measures. subchondral bone loss and most probably a concomitant potential IBM. Leading comorbidities included HIV with anti-retroviral therapy (ART) (including abacavir, lamivudine, and nevirapine) and a long-term proton-pump inhibitor (PPI) prescription (Fig. 1), chronic hypocalcemia, chronic alcohol abuse, and long-term smoking (Fig. 2), severe vitamin D deficiency (Fig. 3), severe osteoporosis defined as a DXA T-score of lower than - 2.5 SD and at least two fragility fractures, as well as an unspecified collagenosis with chronic type-c gastritis, subsequent hypocalcemia, and myasthenia gravis.

\section{Individual failure analysis}

Analyzing the clinically fair and poor cases $(n=6)$ individually resulted in specific findings (Table 6). In all patients, a secondary loss of fixation could be observed due to severe

Table 5 Logistic regression with respect to clinical outcome (Rasmussen: poor and fair/good and excellent)

\begin{tabular}{lrlrrrr}
\hline Variable & \multicolumn{1}{l}{ B } & SE & \multicolumn{1}{c}{ Wald } & df & \multicolumn{1}{l}{ Sig } & Exp (B) \\
\hline Model & 3.461 & 0.885 & 15.302 & 1 & $<0.001$ & 31.847 \\
Metabolic bone disorder & -2.182 & 0.908 & 5.774 & 1 & 0.016 & 0.113 \\
Fracture type (41-type B or C) & 0.621 & 0.879 & 0.499 & 1 & 0.480 & 1.861 \\
\hline
\end{tabular}

Table 6 Individual failure analysis of clinically poor/fair outcome (Rasmussen)

\begin{tabular}{|c|c|c|c|c|c|}
\hline Patient & $\mathrm{AO}$ & $\begin{array}{l}\text { Rasmus- } \\
\text { sen (rad/ } \\
\text { clin) }\end{array}$ & Specific outcome & Patient-related risk factors & Surgery-related risk factors \\
\hline$\# 1(\widehat{\jmath}, 50 \mathrm{y}, 16 \mathrm{~m} \mathrm{FU})$ & $\mathrm{C} 3$ & $14 / 18$ & $\begin{array}{l}\text { - Loss of reduction PLL, PLC, } \\
\text { PMM } \\
\text { - Subchondral substance defect }\end{array}$ & $\begin{array}{l}\text { - HIV infection } \\
\text { - ART } \\
\text { Therapy }\end{array}$ & $\begin{array}{l}\text { - Missing subchondral Jail- } \\
\text { screw } \\
\text { - No posteromedial buttress }\end{array}$ \\
\hline$\# 2(ð, 50 \mathrm{y}, 14 \mathrm{~m} \mathrm{FU})$ & $\mathrm{C} 3$ & $10 / 14$ & $\begin{array}{l}\text { - Loss of reduction } \\
\text { PMM, PMC } \\
\text { - Pseudarthrosis }\end{array}$ & $\begin{array}{l}\text { - Hypocalcemia } \\
\text { - Smoking } \\
\text { - Alcohol abuse }\end{array}$ & $\begin{array}{l}\text { - Screw placement into fracture } \\
\text { gap } \\
\text { - no posteromedial buttress }\end{array}$ \\
\hline \#3 (q, 78y, $24 \mathrm{~m} \mathrm{FU})$ & B2 & $12 / 18$ & $\begin{array}{l}\text { - Subchondral substance defect } \\
\text { with loss of reduction AMC, } \\
\text { AMM }\end{array}$ & $\begin{array}{l}\text { - Hypocalcemia } \\
\text { - Vitamin D deficiency } \\
(3.4 \mathrm{ng} / \mathrm{mL}) \\
\text { - COPD with inhaled corticos- } \\
\text { teroids }\end{array}$ & - \\
\hline \#4 left (q, 62y, $30 \mathrm{~m} \mathrm{FU})$ & B3 & $-/ 19$ & $\begin{array}{l}\text { - Severe pain despite full range } \\
\text { of motion with secondary } \\
\text { loss of reduction AMC, } \\
\text { AMM }\end{array}$ & $\begin{array}{l}\text { - Unspecific collagenosis } \\
\text { - Hypocalcemia } \\
\text { - Chronic type-c gastritis } \\
\text { - Myasthenia gravis }\end{array}$ & - \\
\hline$\# 4$ right $(+9,62 y, 30 \mathrm{~m} \mathrm{FU})$ & B3 & $-/ 19$ & $\begin{array}{l}\text { - Severe pain despite full range } \\
\text { of motion with secondary } \\
\text { loss of reduction AMC, } \\
\text { AMM }\end{array}$ & $\begin{array}{l}\text { - Unspecific collagenosis } \\
\text { - Hypocalcemia } \\
\text { - Chronic type-c gastritis } \\
\text { - Myasthenia gravis }\end{array}$ & - \\
\hline$\# 6(ð, 44 y, 89 \mathrm{~m} \mathrm{FU})$ & $\mathrm{C} 3$ & $14 / 18$ & $\begin{array}{l}\text { - Severe pain due to lateral } \\
\text { knee osteoarthritis } \\
\text { - Loss of reduction PLL, PLC }\end{array}$ & - & $\begin{array}{l}\text { - Insufficient articular recon- } \\
\text { struction of the postero-latero- } \\
\text { central and postero-latero- } \\
\text { lateral segments }\end{array}$ \\
\hline
\end{tabular}

$F U$ follow-up, segments according to ten-segment classification: $A M M$ antero-medio-medial, $A M C$ antero-medio-central, $P M M$ postero-mediomedial, $P M C$ postero-medio-central, $P L L$ postero-latero-central, $P L C$ postero-latero-lateral, $H I V$ humane immune insufficiency, $A R T$ anti-retroviral therapy, $C O P D$ chronic obstructive pulmonary disease, $F U$ follow-up, $m$ months 

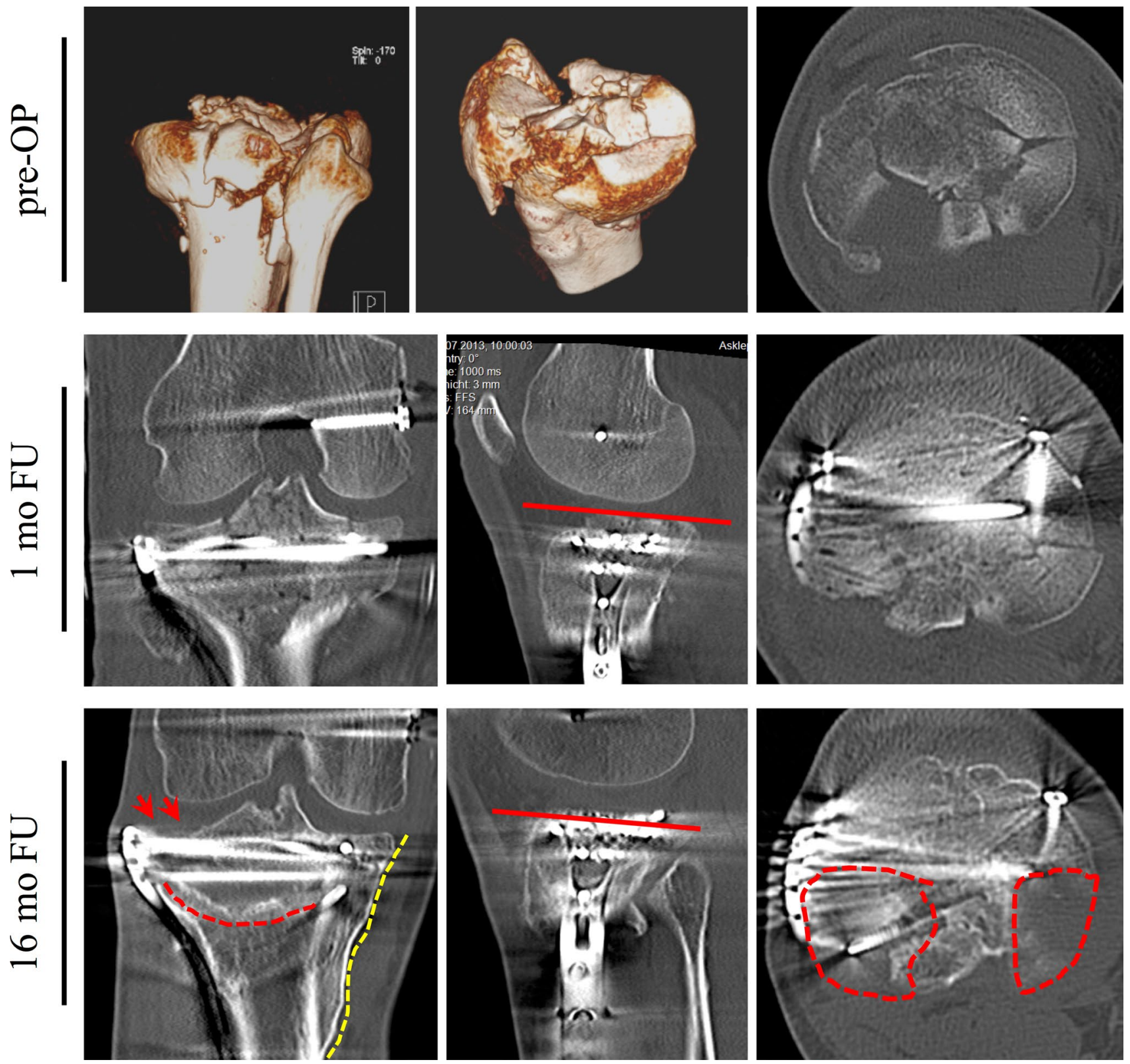

Fig. 1 A 50-year-old male with a bicondylar TPF [AO 41-type C3, medial split, lateral comminution involving the tibial spine and the most severe depression in the postero-latero-central (PLC) segment, pre-OP] after a motorcycle accident. A 1-month follow-up (FU) after lateral unilateral plating and antero-posterior screw fixation of the medial plateau showed anatomic articular reconstruction medially and laterally via an anterolateral and posteromedial approach, including an osteotomy of the medial femoral epicondyle for improved visualization (1-month FU). At the 16-month FU, lateral and medial loss

\section{Discussion}

The present study demonstrated a good-to-excellent clinical outcome in more than $95 \%$ of the cases $[1,27-30]$. Specifically, 41-type B fractures showed a better outcome than that of 41-type $C$ fractures. We found that the presence of of reduction (red arrows in anterior-posterior (ap) view and red line in sagittal view) with a substantial subchondral bone defect (red dotted line in ap view) accompanied with a medial bony union (yellow dotted line) could be observed. Primarily, the postero-latero-lateral and the PLC segments were affected (red dotted line in axial view). The patient presented with bone metabolism-affecting comorbidities, including human immunodeficiency virus with anti-retroviral therapy and a long-term proton-pump inhibitor prescription

potential IBM due to influencing comorbidities or medication was an independent risk factor for a poor or fair clinical outcome, especially in 41-type B fractures. In accordance with the previous studies, a great number of patients with severe bony destruction reported a good-to-excellent clinical outcome despite postoperative radiological peculiarities 

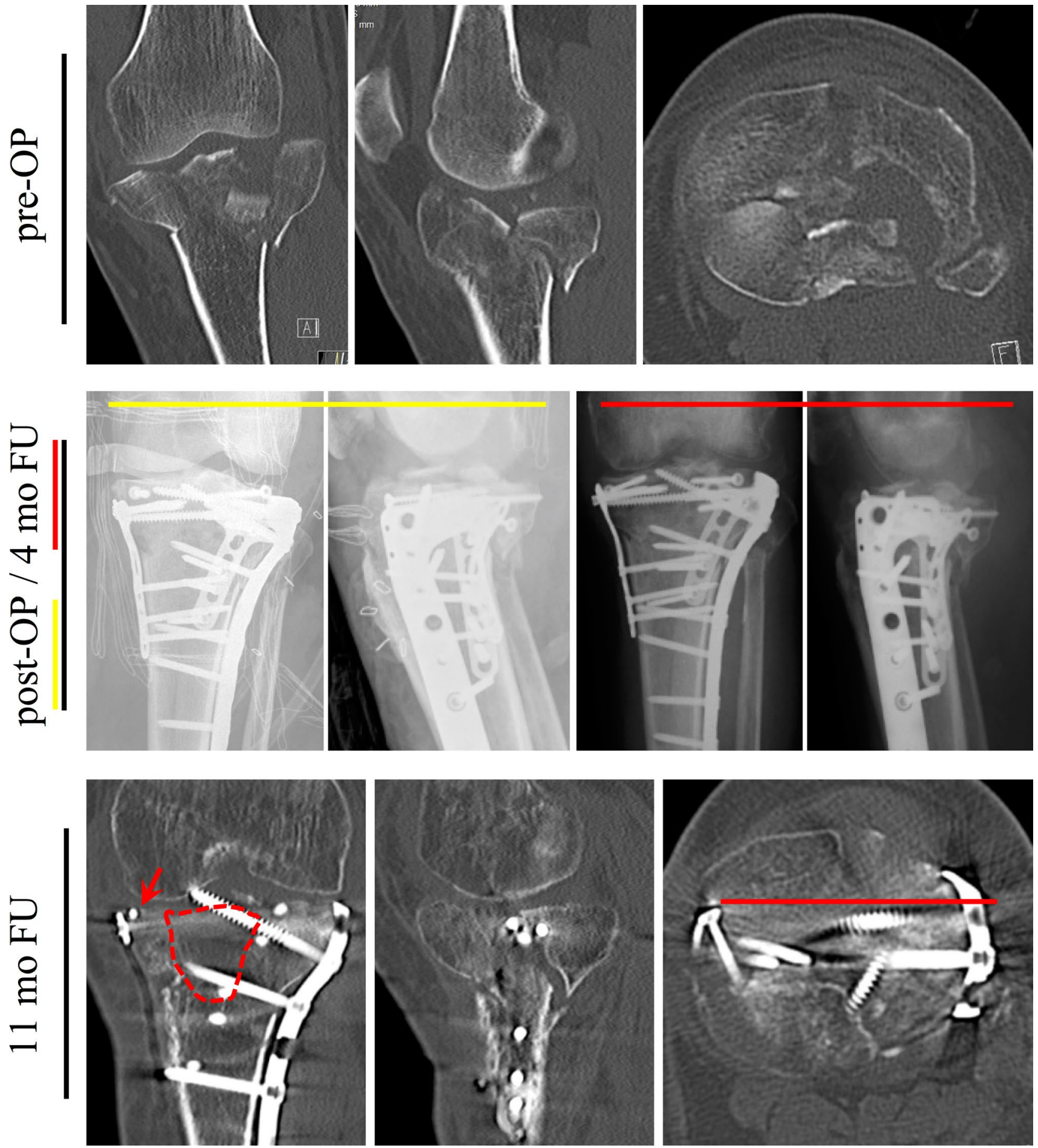

Fig. 2 A 50-year-old male with a bicondylar TPF (AO 41-type C3, medial split, lateral comminution involving the tibial spine and the most severe depression in the postero-latero-central segment, pre-OP) after a fall due to alcohol intoxication. A postoperative X-ray of the lateral and posterolateral reduction with individual plate fixation in addition to anatomic reduction and medial plate fixation of the medial tibial plateau (yellow head line). Medially, an additional jail screw supported subchondral fixation (post-OP). The 4-month follow-up (FU) showed secondary loss of reduction (red arrow in the anterior- posterior view) with a substantial subchondral bone defect (red dotted line), secondary intraarticular screw location, and an osteopenic bone stock (4-mo $F U$ ). The sagittal and axial views revealed an unfortunate screw placement into the fracture gap without providing sufficient stabilization. While the antero-posterior jail screw might not have had enough osteosynthetic subchondral bone support, there was no posteromedial buttress. Comorbidities included chronic hypocalcemia, chronic alcohol abuse, and long-term smoking 

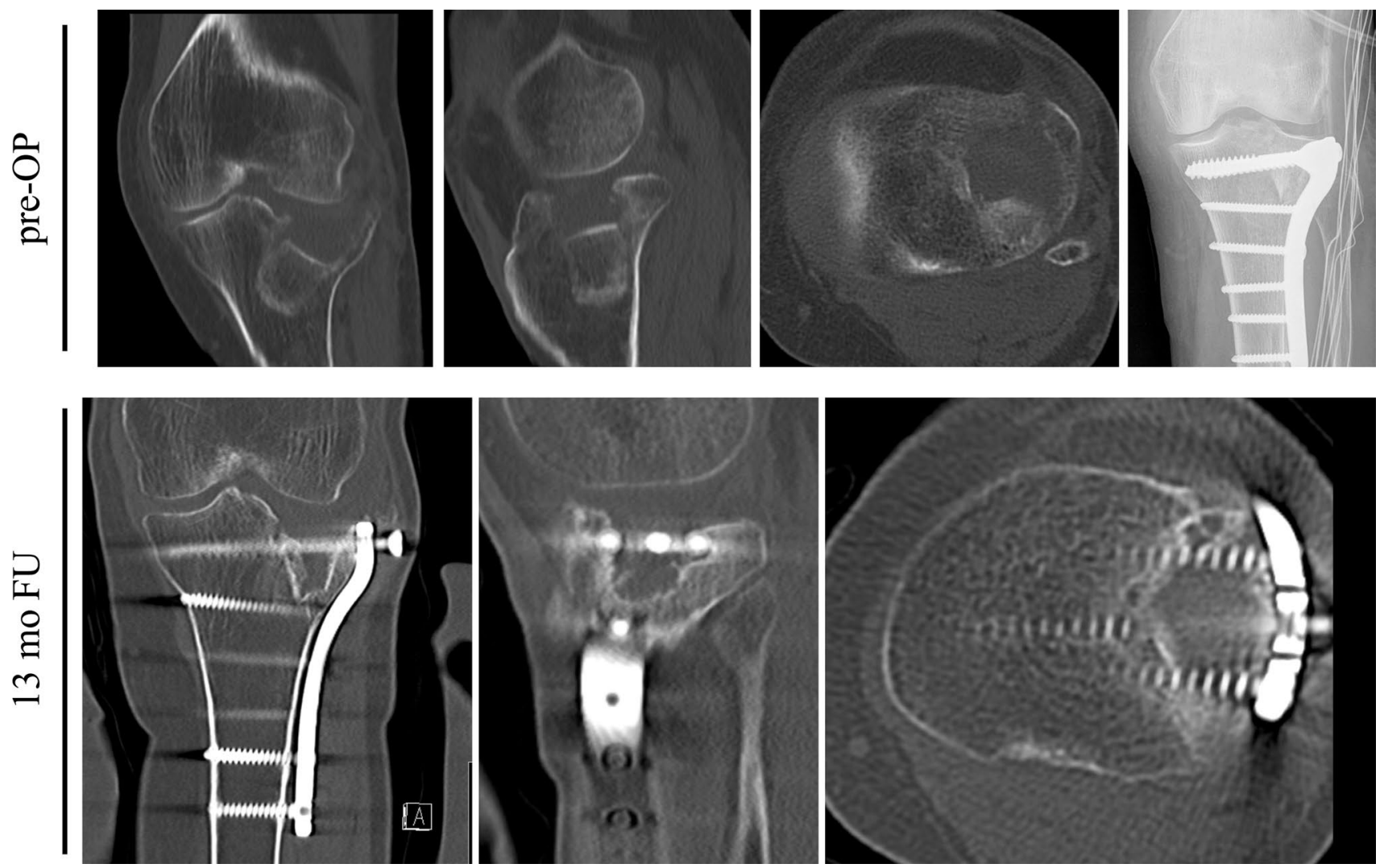

Fig. 3 A 78-year-old female with a lateral depression fracture (AO 41-type B2, involving antero-latero-lateral, antero-latero-central segments, pre-OP) after a trip and fall. Surgical treatment included an anatomic reduction, transplantation with an autogenic corticocancellous iliac crest graft, and fixation with an anterolateral plate.

$[8,14,16,36,37]$ as well as an even better outcome with unilateral plateau fracture $[10,15,38]$.

Common comorbidities, such as type II diabetes or arterial hypertension, have not been associated with clinical outcomes $[6,7,10]$. However, reports analyzing the risk factors of bone metabolism in a cohort of TPF are rare. In the current study, all but one patient with a fair-to-poor clinical outcome demonstrated at least one risk factor for IBM and consequent fracture healing (Table 5). One patient showed secondary loss of reduction in the posterolateral and posteromedial segments, and that patient presented with HIV and ART with abacavir, lamivudine, and nevirapine. HIV itself is a risk factor for impaired fracture healing [39]. Treated patients with HIV have a 1.98-to-3.69 times higher fracture rate compared to healthy controls [40]. In addition, ART regimens induce increased bone loss [41]. However, modern regimens with abacavir-lamivudine and nevirapine have demonstrated fewer decreases in bone mineral density and fewer increases in bone turnover [42]. In addition, the patient was exposed to long-term PPI therapy; this causes iatrogenic hypochlorhydria, which itself is associated with
A computed tomography scan at the 13-month follow-up revealed a severe osteochondral defect with a complete dissolution of the autogenic graft. The patient demonstrated a severe vitamin D deficiency of $3.4 \mathrm{ng} / \mathrm{mL}$ and persistent hypocalcemia

decreased bone mass, decreased bone mineralization, and consequently increased fracture risk [43-45]. PPI-induced hypochlorhydria was also detected in another patient with bilateral fractures and secondary loss of reduction. She presented with chronic type-c gastritis, a subsequent chronic hypocalcemia, and unknown collagenosis, which were responsible for a number of insufficiency fractures in the patient's history. She also suffered from myasthenia gravis, which is associated with significant bone loss independent of corticosteroid use [46]. Common risk factors for delayed fracture healing or fragility fractures, such as chronic alcohol abuse and severe smoking, were not statistically associated with impaired clinical outcomes in the present study, but they may have been one of the major triggers in one patient with secondary loss of reduction and a substantial subchondral bone loss (Fig. 2) [47]. Additionally, vitamin D deficiency was commonly observed, and even though its role in fracture healing is still under debate, it constitutes one of the most important determinants of skeletal health [47, 48].

Numerous studies that have analyzed the outcome of TPF have identified several risk factors for poor clinical and 
radiological outcome, such as fracture complexity, leg axis malreduction [9], involvement of the posterior column [7], residual articular depression of more than $2 \mathrm{~mm}[9,13]$, or postoperative malreduction due to an impaired intraoperative fragment visualization [26, 49], while the impact of associated soft-tissue injuries is still under debate [50,51]. In the individual failure analysis of the present study, two of six cases may be explained solely by a potential IBM. The other four fractures showed secondary loss of reduction. While risk factors for a potential IBM were found in all cases, surgical considerations should also be included. Two cases involved the posterior column with specific involvement of the PLL, PLC, and both posteromedial segments (posteromedial shear fragments) without a supporting posteromedial buttress plate, a direct subchondral screw placement with the strongest bone stock in the tibial plateau, or malreduced posterolateral fragments due to an insufficient initial surgical approach. Addressing the posterior column has been identified as an important prognostic factor with respect to functional outcomes [6, 7].

The most important objective clinical limitation, even in patients with good-to-excellent clinical outcome and especially in 41-type C fractures, was impaired ROM. All patients were encouraged to achieve full ROM within three months after surgery through strict rehabilitation protocols. ROM may still be improved up until the sixth month after surgery, but it may be impaired afterwards if it is not fully accomplished by the sixth month [52]. The most important risk factor is time spent on the external fixator and bicondylar fracture involvement, which is supported by the present results [53]. Hence, limited ROM in TPF is common and should be the focus of postoperative rehabilitation [53, 54].

This study has some limitations. Due to its retrospective nature, data acquisition was based on patient records without a standardized assessment of systemic bone mineral disorders, including dual-energy X-ray absorptiometry or serum analyses of $25-\mathrm{OH}$ vitamin $\mathrm{D}$, phosphate, or creatinine levels. All medical records were carefully screened, with a special emphasis on calcium levels and secondary indicators for potential IBM. Additionally, given the complexity of different fracture patterns, the methods of ORIF differed among the fracture types, resulting in treatment bias [5, 37]. However, this limitation reflects everyday clinical practice in orthopedic trauma surgery [15]. In addition, postoperative CT scans were performed in only 28 patients. However, radiological evaluation to assess the Rasmussen score is established on plain radiographs $[33,55]$.

\section{Conclusion}

In this multicenter retrospective cohort study, the mid-tolong-term clinical outcome after ORIF of TPF was goodto-excellent in the vast majority of the cases. Potential IBM was an independent risk factor for a poor-to-fair clinical outcome. The most important functional limitation was impaired ROM.

Funding Open Access funding enabled and organized by Projekt DEAL.

\section{Compliance with ethical standards}

Conflict of interest All authors declare that they have no conflict of interest.

Open Access This article is licensed under a Creative Commons Attribution 4.0 International License, which permits use, sharing, adaptation, distribution and reproduction in any medium or format, as long as you give appropriate credit to the original author(s) and the source, provide a link to the Creative Commons licence, and indicate if changes were made. The images or other third party material in this article are included in the article's Creative Commons licence, unless indicated otherwise in a credit line to the material. If material is not included in the article's Creative Commons licence and your intended use is not permitted by statutory regulation or exceeds the permitted use, you will need to obtain permission directly from the copyright holder. To view a copy of this licence, visit http://creativecommons.org/licenses/by/4.0/.

\section{References}

1. Krause M, Preiss A, Muller G, Madert J, Fehske K, Neumann MV, et al. Intra-articular tibial plateau fracture characteristics according to the "Ten segment classification." Injury. 2016;47(11):25517. https://doi.org/10.1016/j.injury.2016.09.014.

2. Hoekstra H, Kempenaers K, Nijs S. A revised 3-column classification approach for the surgical planning of extended lateral tibial plateau fractures. Eur J Trauma EmergSurg. 2017;43(5):637-43. https://doi.org/10.1007/s00068-016-0696-z.

3. Patzold R, Friederichs J, von Ruden C, Panzer S, Buhren V, Augat $\mathrm{P}$. The pivotal role of the coronal fracture line for a new three-dimensional CT-based fracture classification of bicondylar proximal tibial fractures. Injury. 2017;48(10):2214-20. https:// doi.org/10.1016/j.injury.2017.06.019.

4. Wang Y, Luo C, Zhu Y, Zhai Q, Zhan Y, Qiu W, et al. Updated three-column concept in surgical treatment for tibial plateau fractures: a prospective cohort study of 287 patients. Injury. 2016;47(7):1488-96. https://doi.org/10.1016/j.injury.2016.04.026.

5. Frosch KH, Korthaus A, Thiesen D, Frings J, Krause M. The concept of direct approach to lateral tibial plateau fractures and stepwise extension as needed. Eur J Trauma EmergSurg. 2020. https://doi.org/10.1007/s00068-020-01422-0.

6. Quintens L, Van den Berg J, Reul M, Van Lieshout E, Nijs S, Verhofstad M, et al. Poor sporting abilities after tibial plateau fractures involving the posterior column: how can we do better? Eur J Trauma EmergSurg. 2019. https://doi.org/10.1007/s0006 8-019-01220-3.

7. van den Berg J, Nijs S, Hoekstra H. Limited value of the column concept in the operative management of posterior column tibial 
plateau fractures. Eur J Trauma EmergSurg. 2019. https://doi. org/10.1007/s00068-019-01078-5.

8. Rohra N, Suri HS, Gangrade K. Functional and radiological outcome of schatzker type V and VI tibial plateau fracture treatment with dual plates with minimum 3 years follow-up: a prospective study. J ClinDiagn Res. 2016;10:5. https://doi.org/10.7860/ JCDR/2016/18732.7855 (RC05-10)

9. Rademakers MV, Kerkhoffs GM, Sierevelt IN, Raaymakers EL, Marti RK. Operative treatment of 109 tibial plateau fractures: fiveto 27-year follow-up results. J Orthop Trauma. 2007;21(1):5-10. https://doi.org/10.1097/BOT.0b013e31802c5b51.

10. Hap DXF, Kwek EBK. Functional outcomes after surgical treatment of tibial plateau fractures. J ClinOrthop Trauma. 2020;11(Suppl 1):S11-5. https://doi.org/10.1016/j. jcot.2019.04.007.

11. Parkkinen M, Lindahl J, Makinen TJ, Koskinen SK, Mustonen A, Madanat R. Predictors of osteoarthritis following operative treatment of medial tibial plateau fractures. Injury. 2018;49(2):370-5. https://doi.org/10.1016/j.injury.2017.11.014.

12. Honkonen SE. Indications for surgical treatment of tibial condyle fractures. ClinOrthopRelat Res. 1994;302:199-205.

13. Singleton N, Sahakian V, Muir D. Outcome after tibial plateau fracture: how important is restoration of articular congruity? J Orthop Trauma. 2017;31(3):158-63. https://doi.org/10.1097/ BOT.0000000000000762.

14. Prasad GT, Kumar TS, Kumar RK, Murthy GK, Sundaram N. Functional outcome of Schatzker type V and VI tibial plateau fractures treated with dual plates. Indian J Orthop. 2013;47(2):18894. https://doi.org/10.4103/0019-5413.108915.

15. Baumlein M, Hanke A, Gueorguiev B, Nerlich M, Liodakis E, Perren T, et al. Long-term outcome after surgical treatment of intra-articular tibial plateau fractures in skiers. Arch Orthop Trauma Surg. 2019;139(7):951-9. https://doi.org/10.1007/s0040 2-019-03150-6.

16. Hong G, Huang X, Lv T, Li X. An analysis on the effect of the three-incision combined approach for complex fracture of tibial plateau involving the posterolateraltibial plateau. J OrthopSurg Res. 2020;15(1):43. https://doi.org/10.1186/s13018-020-1572-4.

17. Dincel YM, Oner A, Arikan Y, Caglar S, Ozcafer R, Gulec MA. Effect of BMI on outcomes of surgical treatment for tibial plateau fractures: a comparative retrospective case series study. Chin J Traumatol. 2018;21(2):104-8. https://doi.org/10.1016/j.cjtee .2017.10.005.

18. Gorter EA, Krijnen P, Schipper IB. Vitamin D status and adult fracture healing. J ClinOrthop Trauma. 2017;8(1):34-7. https:// doi.org/10.1016/j.jcot.2016.09.003.

19. Zhu H, Zhang J, Wang J, Zhao X, Gu M. Association of subclinical thyroid dysfunction with bone mineral density and fracture: a meta-analysis of prospective cohort studies. Endocrine. 2020;67(3):685-98. https://doi.org/10.1007/s12020-019-02110-9.

20. Vilaca T, Salam S, Schini M, Harnan S, Sutton A, Poku E, et al. Risks of hip and nonvertebral fractures in patients with CKD G3a-G5D: a systematic review and meta-analysis. Am J Kidney Dis. 2020. https://doi.org/10.1053/j.ajkd.2020.02.450.

21. Hill NR, Fatoba ST, Oke JL, Hirst JA, O'Callaghan CA, Lasserson DS, et al. Global prevalence of chronic kidney disease: a systematic review and meta-analysis. PLoS ONE. 2016;11(7):e0158765. https://doi.org/10.1371/journal.pone.0158765.

22. Cashman KD, Dowling KG, Skrabakova Z, Gonzalez-Gross M, Valtuena J, De Henauw S, et al. Vitamin D deficiency in Europe: pandemic? Am J ClinNutr. 2016;103(4):1033-44. https://doi. org/10.3945/ajen.115.120873.

23. Blum MR, Bauer DC, Collet TH, Fink HA, Cappola AR, da Costa BR, et al. Subclinical thyroid dysfunction and fracture risk: a meta-analysis. JAMA. 2015;313(20):2055-65. https://doi. org/10.1001/jama.2015.5161.
24. Looker AC, Orwoll ES, Johnston CC Jr, Lindsay RL, Wahner HW, Dunn WL, et al. Prevalence of low femoral bone density in older U.S. adults from NHANES III. J Bone Miner Res. 1997;12(11):1761-8. https://doi.org/10.1359/ jbmr.1997.12.11.1761

25. AWMF. Prophylaxis, diagnosis and therapy of osteoporosis. 2019. Register number: AWMF-Register-Nr.: 183/001. https:// www.awmf.org/uploads/tx_szleitlinien/183-0011_S3_Osteoporos e-Prophylaxe-Diagnostik-Therapie_2019-02.pdf

26. Krause M, Preiss A, Meenen NM, Madert J, Frosch KH. "Fracturoscopy" is superior to fluoroscopy in the articular reconstruction of complex tibial plateau fractures-an arthroscopy assisted fracture reduction technique. J Orthop Trauma. 2016;30(8):43744. https://doi.org/10.1097/BOT.0000000000000569.

27. Krause M, Frosch KH. Response to the letter-to-the-editor by Dhillon et al. "Simple four column classification can dictate treatment for intra articular tibial plateau fractures much better than ten segment classification", Injury 2017. Injury. 2017;48(10):2369_ 70. https://doi.org/10.1016/j.injury.2017.07.040.

28. Krause M, Menzdorf L, Preiss A, Frosch KH. Are there four tibial plateau columns? Yes there are, as illustrated by a postero-lateral apple-bite fracture. Response to a letter-to-the-editor. IntOrthop. 2018;42(2):443-6. https://doi.org/10.1007/s00264-017-3686-9.

29. Krause M, Kruger S, Muller G, Puschel K, Frosch KH. How can the articular surface of the tibial plateau be best exposed? A comparison of specific surgical approaches. Arch Orthop Trauma Surg. 2019. https://doi.org/10.1007/s00402-019-03200-z.

30. Krause M, Muller G, Frosch KH. Surgical approaches to tibial plateau fractures. Unfallchirurg. 2018. https://doi.org/10.1007/ s00113-018-0515-6.

31. Krause M, Muller G, Frosch KH. Extended medial and extended lateral approach for tibial plateau fractures. OperOrthopTraumatol. 2019;31(2):127-42. https://doi.org/10.1007/s0006 4-019-0593-9.

32. Rasmussen PS. Tibial condylar fractures. Impairment of knee joint stability as an indication for surgical treatment. J Bone JtSurg Am. 1973;55(7):1331-50.

33. Chan YS, Chiu CH, Lo YP, Chen AC, Hsu KY, Wang CJ, et al. Arthroscopy-assisted surgery for tibial plateau fractures: 2- to 10-year follow-up results. Arthroscopy. 2008;24(7):760-8. https ://doi.org/10.1016/j.arthro.2008.02.017.

34. Eggli S, Hartel MJ, Kohl S, Haupt U, Exadaktylos AK, Roder C. Unstable bicondylartibial plateau fractures: a clinical investigation. J Orthop Trauma. 2008;22(10):673-9. https://doi. org/10.1097/BOT.0b013e31818b1452.

35. Holick MF. Vitamin D deficiency. N Engl J Med. 2007;357(3):266-81. https://doi.org/10.1056/NEJMra070553.

36. Weigel DP, Marsh JL. High-energy fractures of the tibial plateau. Knee function after longer follow-up. J Bone JtSurg Am. 2002;84(9):1541-51. https://doi.org/10.2106/00004623-20020 9000-00006

37. Song Z, Wang Q, Ma T, Wang C, Yang N, Xue H, et al. Failure analysis of primary surgery and therapeutic strategy of revision surgery for complex tibial plateau fractures. J OrthopSurg Res. 2019;14(1):110. https://doi.org/10.1186/s13018-019-1147-4.

38. van Dreumel RL, van Wunnik BP, Janssen L, Simons PC, Janzing HM. Mid- to long-term functional outcome after open reduction and internal fixation of tibial plateau fractures. Injury. 2015;46(8):1608-12. https://doi.org/10.1016/j.injury.2015.05.035.

39. Richardson J, Hill AM, Johnston CJ, McGregor A, Norrish AR, Eastwood D, et al. Fracture healing in HIV-positive populations. J Bone JtSurg Br. 2008;90(8):988-94. https://doi.org/10.1302/0301620X.90B8.20861.

40. Young B, Dao CN, Buchacz K, Baker R, Brooks JT, Investigators HIVOS. Increased rates of bone fracture among HIV-infected persons in the HIV outpatient study (HOPS) compared with the US 
general population, 2000-2006. Clin Infect Dis. 2011;52(8):10618. https://doi.org/10.1093/cid/ciq242.

41. Brown TT, Qaqish RB. Antiretroviral therapy and the prevalence of osteopenia and osteoporosis: a meta-analytic review. AIDS. 2006;20(17):2165-74. https://doi.org/10.1097/QAD.0b013e3280 $1022 \mathrm{eb}$.

42. Negredo E, Domingo P, Perez-Alvarez N, Gutierrez M, Mateo G, Puig $\mathrm{J}$, et al. Improvement in bone mineral density after switching from tenofovir to abacavir in HIV-1-infected patients with low bone mineral density: two-centre randomized pilot study (OsteoTDF study). J AntimicrobChemother. 2014;69(12):3368-71. https://doi.org/10.1093/jac/dku300.

43. Schinke T, Schilling AF, Baranowsky A, Seitz S, Marshall RP, Linn T, et al. Impaired gastric acidification negatively affects calcium homeostasis and bone mass. Nat Med. 2009;15(6):674-81. https://doi.org/10.1038/nm.1963.

44. Yang YX, Lewis JD, Epstein S, Metz DC. Long-term proton pump inhibitor therapy and risk of hip fracture. JAMA. 2006;296(24):2947-53. https://doi.org/10.1001/ jama.296.24.2947.

45. Krause M, Keller J, Beil B, van Driel I, Zustin J, Barvencik F, et al. Calcium gluconate supplementation is effective to balance calcium homeostasis in patients with gastrectomy. OsteoporosInt. 2015;26(3):987-95. https://doi.org/10.1007/s00198-014-2965-1.

46. Yeh JH, Chen HJ, Chen YK, Chiu HC, Kao CH. Increased risk of osteoporosis in patients with myasthenia gravis: a populationbased cohort study. Neurology. 2014;83(12):1075-9. https://doi. org/10.1212/WNL.0000000000000804.

47. Chiavarini M, Naldini G, Fabiani R. The role of diet in osteoporotic fracture healing: a systematic review. CurrOsteoporos Rep. 2020. https://doi.org/10.1007/s11914-020-00573-8.

48. Reid IR, Bolland MJ. Calcium and/or vitamin D supplementation for the prevention of fragility fractures: who needs it? Nutrients. 2020;12:4. https://doi.org/10.3390/nu12041011.
49. Meulenkamp B, Martin R, Desy NM, Duffy P, Korley R, Puloski $\mathrm{S}$, et al. Incidence, risk factors, and location of articular malreductions of the tibial plateau. J Orthop Trauma. 2017;31(3):146-50. https://doi.org/10.1097/BOT.0000000000000735.

50. Warner SJ, Garner MR, Schottel PC, Fabricant PD, Thacher RR, Loftus ML, et al. The effect of soft tissue injuries on clinical outcomes after tibial plateau fracture fixation. J Orthop Trauma. 2018;32(3):141-7. https://doi.org/10.1097/BOT.0000000000 001042 .

51. Cinque ME, Godin JA, Moatshe G, Chahla J, Kruckeberg BM, Pogorzelski J, et al. Do tibial plateau fractures worsen outcomes of knee ligament injuries? A matched cohort analysis. Orthop J Sports Med. 2017;5(8):2325967117723895. https://doi. org/10.1177/2325967117723895.

52. Christiano AV, Pean CA, Kugelman DN, Konda SR, Egol KA. Function and knee range of motion plateau six months following lateral tibial plateau fractures. J Knee Surg. 2019. https://doi. org/10.1055/s-0039-1678676.

53. Reahl GB, Marinos D, O'Hara NN, Howe A, Degani Y, Wise B, et al. Risk factors for knee stiffness surgery after tibial plateau fracture fixation. J Orthop Trauma. 2018;32(9):e339-43. https:// doi.org/10.1097/BOT.0000000000001237.

54. Kugelman DN, Qatu AM, Strauss EJ, Konda SR, Egol KA. Knee stiffness after tibial plateau fractures: predictors and outcomes (OTA-41). J Orthop Trauma. 2018;32(11):e421-7. https://doi. org/10.1097/BOT.0000000000001304.

55. Korthaus A, Ballhause TM, Kolb JP, Krause M, Frosch KH, Hartel MJ. Extended approach to the lateral tibial plateau with central meniscal subluxation in fracture repair: feasibility and first clinical and radiographic results. Eur J Trauma EmergSurg. 2020. https:// doi.org/10.1007/s00068-020-01467-1. 